\title{
Revizyon diz cerrahisinde komponentlerin çıkarılması
}

\author{
Removing components in revision knee surgery
}

\author{
Burak Akan ${ }^{1}$, Cihan Kırçıl' ${ }^{2}$ illker Çetin ${ }^{3}$ \\ ${ }^{1}$ Ufuk Üniversitesi, Ortopedi ve Travmatoloji Anabilim Dalı, Ankara \\ ${ }^{2}$ Özel Liv Ankara Hastanesi, Ortopedi ve Travmatoloji Kliniği, Ankara \\ ${ }^{3}$ Özel Medicana Hastanesi, Ortopedi ve Travmatoloji Kliniği, Ankara
}

\begin{abstract}
Revizyon cerrahisinde güvenli ve etkili bir şekilde implant çıkarımı çok önemlidir. İmplant çıkarımı esnasında gereksiz ve aşırı kemik kaybı, aşırı zaman harcanması, özellikle tek aşamalı revizyonlarda veya ekstansör mekanizma gibi önemli yapılara zarar verilmesi sonrasında yapılacak cerrahileri ve sonuçlarını etkiler. Bu yüzden, revizyon cerrahisi öncesi veya revizyon cerrahisi esnasında implant çıkarımı sistematik bir düzen içerisinde planlı bir şekilde yapılmalıdır.
\end{abstract}

Anahtar sözcükler: revizyon; diz; artroplasti; implant çıkarma
In revision surgery, safe and effective implant removal is vital. Whilst removing the implant, extensive unnecessary bone loss, excessive surgery time especially in one stage revision, or damage to essential tissue such as extensor mechanism can have adverse effects in the reconstructive phase of surgery and final outcome. Therefore, a systematic approach to implant removal is imperative, before and throughout any revision surgery.

Key words: revision; knee; arthroplasty; implant removal

herhangi bir malzeme, örneğin implanta özel tornavida gerekli mi?

- İmplant çıkarımı esnasında ne kadar kemik kaybı olabilir? Eğer aynı seansta bir sonraki revizyon cerrahisi de yapılacaksa, bu aşamada beklenmedik kemik kayıplarının rekonstrüksiyonu için gerekli materyal var mı? Örneğin allogreftler, metal bloklar vb.

- Katastrofik herhangi bir komplikasyonda, örneğin kırık durumunda, nasıl bir çözüm bulacağız?

\section{Endikasyonlar ve Kontrendikasyonlar}

İyi fikse edilmiş bir total diz protezinde komponentlerin çıkartılması endikasyonu, bir sonraki revizyon cerrahisi ile optimum sonuçların sağlanabileceği tüm koşulları içerir. Bu koşullar içerisinde; enfeksiyon nedeni ile yapılan tek veya çift aşamalı revizyon cerrahiler, instabilite nedeni ile daha kısıtlı implant kullanımının gerekli olduğu şartlar, aseptik gevşeme, malpozisyon gibi nedenlerden dolayı revizyon cerrrahisi gereken durumlar, bazı özel durumlarda periprostetik kırıklı hastalarda implantların değişmesinin gerektiği şartlar,

- Illetişim adresi: Doç. Dr. Burak Akan, Ufuk Üniversitesi, Dr. Rıdvan Ege Hastanesi, Ortopedi ve Travmatoloji Anabilim Dalı, Ankara Tel: 0505 - 5025327 e-posta: burakakan1977@yahoo.co.uk

- Geliștarihi: 8 Nisan 2015 Kabul tarihi: 8 Nisan 2015 
ara-yüzey (insert) aşınmasının olduğu bazı durumlar gibi, aslında revizyon total diz protezi cerrahisi endikasyonu olan tüm koşullar vardır.

İmplant çıkarımının kontrendikasyonu olarak; implant çıkarımının, cerrahi sonuçları olumlu olarak etkilemeyeceği veya olumsuz etkileyebileceği durumları gösterebiliriz. Bazı şartlarda, bütün komponentlerin çıkartılması gerekmeyebilir. Örneğin, ciddi polietilen hasarı olmayan dome-şekilli bir patellar komponent, çoğu femoral troklear olukla uyumludur. Böyle bir durumda, iyi fikse edilmiş bir patellar komponent, uygun şartlarda femoral ve tibial komponentlerin revizyonuna eşlik ettirilmeyebilir. ${ }^{[2]}$

\section{Aletler ve Cerrahi Planlama}

İmplant çıkarımı öncesi cerrahi plandaki en önemli aşama, bizce, revizyon cerrahisi endikasyonunun tam ve doğru olarak konulmasıdır. Bunun için de, revizyon öncesi revizyonu gerektiren nedenler iyi bilinmeli, aseptik revizyon düşünülen durumlarda, enfeksiyon olasılığı kesin olarak ekarte edilmelidir. Cerrahi planlamada, daha sonraki aşamalarda hangi cerrahi yaklaşımların kullanılacağı, implant çıkarımı için hangi aletlerin gerekeceği belli olmalıdır. İmplant çıkarımı sırasında mutlaka iyi bir eklem açıklığı (exposure) sağlanmalıdır. Önceki cilt kesileri değerlendirilmeli ve unutulmamalı; diz seviyesinde cilt beslenmesi mediyalden olduğu için, doku nekrozu ihtimalini azaltmak amacıyla, çoklu cilt insizyonu varlığında en lateraldeki insizyon kullanılmaya çalışıımalıdır. Standart mediyal parapatellar artrotominin yetersiz kaldığı durumlarda, genişletilmiş yaklaşımlar kullanılmalıdır. İmplant çıkarılırken, ekstansör mekanizmanın bütünlüğünün korunmasına hem eklemin açılması (exposure) hem de komponentlerin çıkarımı esnasında özen gösterilmelidir. Cerrahi öncesi grafilerde; tüberositas tibiadaki ankor, serklaj teli gibi materyallerin görülmesi, daha önceki cerrrahilerde ekstansör mekanizmanın hasarlandığının ve tamir edildiğinin göstergesi olabilir. Böyle durumlarda, ekstansör mekanizmayı riske atmamak için, başlangıc seçeneği olarak, kuadriseps snip gibi genişletilmiş cerrahi yaklaşımlar kullanılabilir.

Cerrahi öncesi, içerideki implantın markası ve modeli anlaşılmaya çalışılmalı ve eğer mümkünse, bu komponentlere özel çıkartıcı aletler temin edilmelidir. İmplant çıkarımı için gerekli aletleri; el aletleri ve güç kaynaklı aletler olarak, başlıca ikiye ayırabiliriz. El aletleri içerisinde, çeşitli kalınlık ve genişlikte osteotomlar, keskiler (chisel) mutlaka olmalıdır. Bunlar, çimento-protez aralığında çalışmak için çok etkilidir. Yine iyi kalitede punch'lar, özellikle stem çıkarımında ve kanal içindeki çimento temizliğinde yararlıdır. Bir diğer önemli el aleti ise 'gigli teli'dir. Gigli teli, gerek femoral komponentin gerekse tibial komponentin çıkarılmasında, usulüne uygun kullanılırsa çok kullanışlıdır. Güç kaynağı kullanan aletler arasında, testere olmazsa olmazdır. Testere bıçaklarının, özellikle dar ve hem uçtan hem yandan dişli olanlarının tercih edilmesi durumunda, bu aletler hem çimento-protez hem de çimentosuz protezlerin çıkartılmasında olduğu gibi, kemik-protez arasında kesi yapmakta da çok etkilidir (Şekil 1). Metal kesen enstrümanlar ise, iyi fikse olmuş implantları parçalara ayırmakta, gerekli durumlarda pegleri kesmekte veya iyi fikse edilmiş stemli femoral ya da tibial komponentleri çıkarmakta vazgeçilmezdir. Ayrıca, çimentoyu eriten ve kesen ultrasonik aletler, çimento-protez aralığında çalışmakta veya intramedüller çimento temizliğinde etkin güç kaynaklı aletlerdir. ${ }^{[3]}$

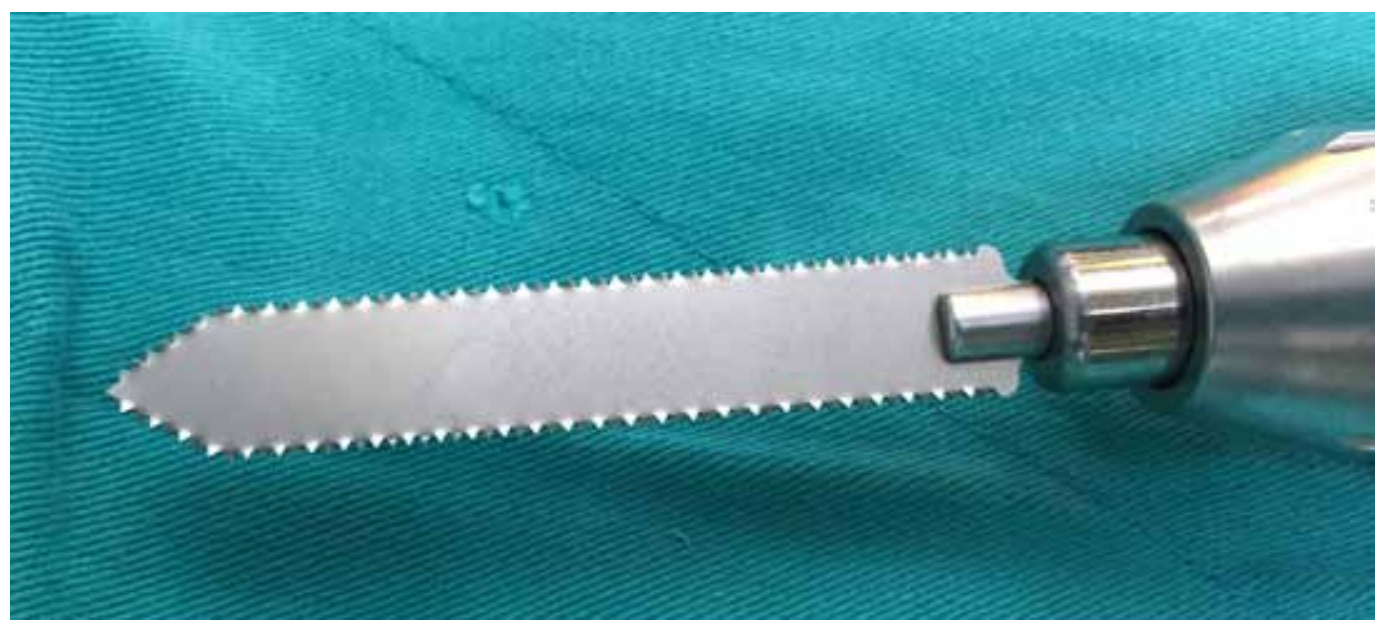

Şekil 1. Çift taraflı ince testere bıçağı. 


\section{Komponentlerin Çıkarılma Sırası}

Genelde ilk çıkarılan komponet insert'tir. Insert'in çıkarılması, diğer komponetlerin çıkarılması esnasında yeterli bir çalışma alanı, yani iyi bir açıklık (exposure) elde edilmesini sağlar. Eğer bütün komponentler çıkarılacak ise, bizim tercih ettiğimiz sıralama; femur, tibia ve son olarak patelladır. Cerrahi esnasında, kemik stok ve yumuşak dokulara zarar vermeyecek şekilde sıralama değiştirilerek, farklı bir tercih yapılabilir.

\section{CERRAHI TEKNIK}

\section{Polietilen Insert Çıkarılması}

Genellikle polietilen insert çıkarımı kolaydır. Tibianın, femur distal yüzeyine yerleştirilen bir Hoffman ekartörü ile öne alınması ve patellanın kenara çekilmesi ya da everte edilmesi sonrası, polietilen insert ile tibial base plate arasına osteotom ile girilir ve insert genellikle kanırtılarak çıkartılabilir (Şekil 2). Bazı tasarımlarda, vida veya kama şeklinde kilit mekanizması bulunabilir. Böyle bir durumda, öncelikle bu kilit mekanizma çözülmeye çalışılmalıdır. Cerrahi öncesi planlama yapılırken, bu tür tasarımlar tanımlanmalı ve kilit mekanizmasına özel tornavida gibi özel aletler var ise temin edilmeye çalışılmalıdır. Kilit mekanizmasının çözülemediği durumlarda, insert, tibial base plate ile birlikte bir bütün olarak veya kesilerek, parça parça çıkarılabilir. Tamamı polietilen insert olan ve tibial metal base plate komponentin olmadığı tasarımlarda, testere ile polietilen insert-çimento arasında kesi yapılarak, insert çıkartılır. Bu tasarımlarda, eğer polietilen tibial stem kesilirse, tibia içindeki stem, içine yerleştirilen bir vida yardımı ile çıkartılabilir.

\section{Femoral Komponentin Çıkartılması}

Ameliyat öncesi radyografilerde bariz gevşeme gözlenen olgularda bile; cerrahi sırasında, komponent, çimento ve kemik arası mesafeler özenli bir şekilde birbirlerinden ayrılmalıdır. ${ }^{[4]}$ Aksi takdirde, çok gevşek bir femoral komponentin çıkartılmasında dahi femur kondilinin kırılması işten bile değildir. Yeterli bir açma (exposure) sonrasında, femoral komponentin anterior ve superior yüzeyinden başlanarak, implant ile çimento arasında bir testere ile bir kesi yapılır. Bu kesi, testere yardımı ile, komponentin yüzeylerine paralel şekilde, anterior yüzden distal yüze doğru peglere veya eğer bağ kesen bir femoral komponent ise femoral box'a kadar ilerletilir (Şekil 3). Bu kesi, gigli

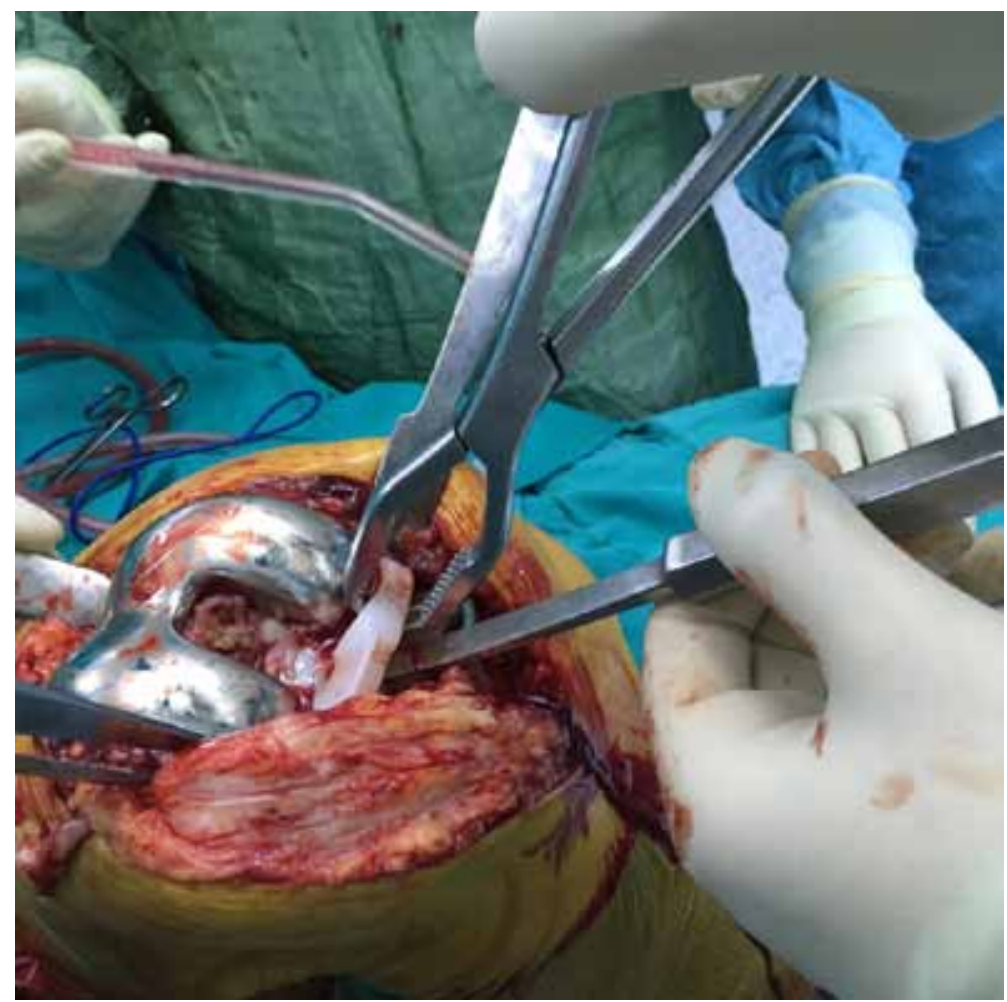

Şekil 2. Aslan dişli kemik klembi ve osteotom yardımı ile polietilen insert çıkartılması. 


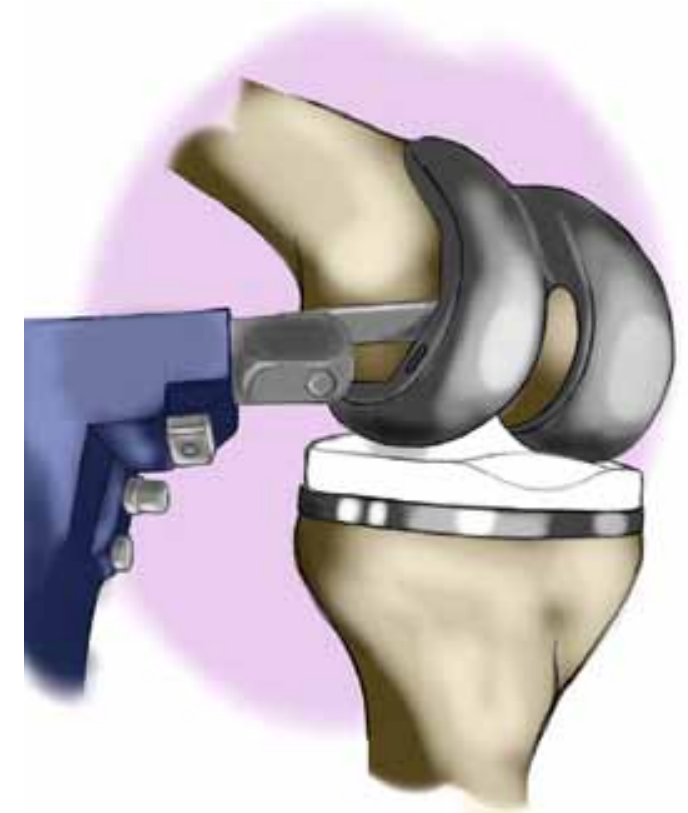

Şekil 3. Femoral komponent altında çimento-implant arasında testere kullanımı.

teli yardımı ile de kolayca yapılabilir (Şekil 4). Box veya peglerin distalinde ise, osteotomlar veya ince uçlu testereler yardımı ile çimento-implant arasında çalışılarak, femoral komponentin gevşemesi sağlanır. Yeterli gevşemeden emin olduktan sonra, varsa özel femoral çıkartıcılar, yoksa disimpaktörler yardımı ile, femoral komponent kuvvetli olmayan çekiç darbeleri ile çıkartılır. Bu aşamada; impaktörün yönüne dikkat edilmeli, gevşemenin yeterli olduğundan emin olunmalı, kuvvetli çekiç darbelerinden kaçınılmalı ve femoral komponente kemikte kırık oluşturabilecek rotasyon hareketleri yaptırılmamalıdır.

İyi fikse edilmiş, çimentosuz, poroz kaplı femoral komponentlerin çıkartılması zor olabilir. ${ }^{[5]}$ Özel tasarlanmış enstrümanlar, bu çıkartılma işlemini kolaylaştırmaktadır. Komponent çıkarımı için tasarlanmış, çeşitli kavrayıcı mekanizmalar ile entegre olabilen, büyük, kayan çekiçler buna örnek verilebilir (Şekil 5). Çimetosuz femoral komponet çıkarımı esnasında, kesi implant-kemik arasından dikkatlice yapılarak, minimal kemik kaybı ile implant çıkarılmalıdır.

\section{Tibial Komponentin Çıkarılması}

Daha öncede bahsedildiği gibi, ilk olarak femoral komponentin çıkartılması -sonrasında tibial komponent üzerinde daha rahat çalışma ortamı oluşturacağı için- tercih edilmelidir. Tibial komponent çıkarımı esnasında, mediyal ve anterior yüzey ilk çalışma alanı

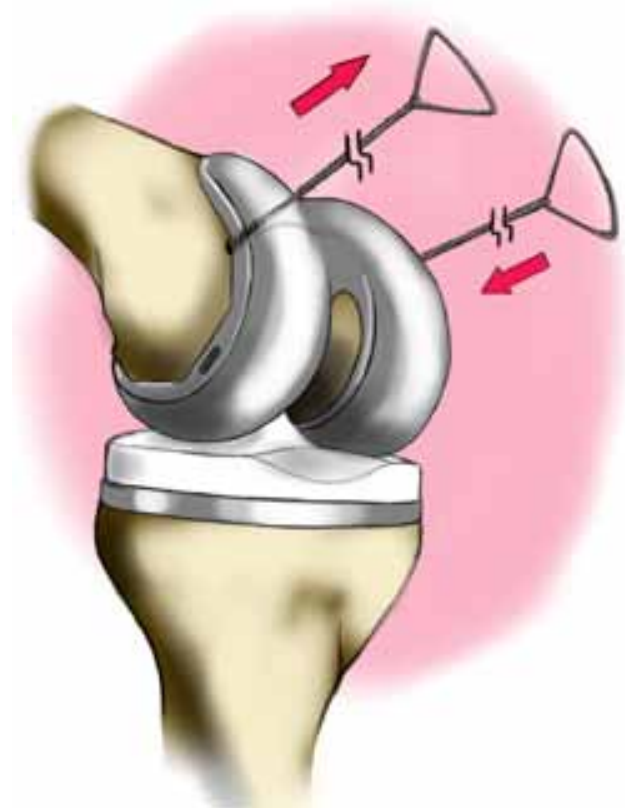

Şekil 4. Femoral komponent altında çimento-implant arasında gigli teli kullanımı.

olarak seçilmelidir. Mediyal posterior taraftaki posteriomediyal kapsül, semimembranöz tendon gevşetilerek tibianın eksternal rotasyonu sağlanır. Böylece, tibianın posterio-mediyalinde çalışma imkanı yaratılır. [1] Yine femoral komponentte olduğu gibi, çimento ile kemik arasının iyi açılması (exposure) burada da esastır. Testere ve osteotomlar yardımı ile, implant-çimento arası mesafede tibial komponent yüzeyine parallel olacak şekilde, implant ile çimentoyu ayırmaya çalışııır. Tibial stem ve pegler, testerenin veya osteotomların anteriordan posteriora geçmesine tam olarak izin vermez. Eksternal rotasyondaki bir tibiada, böyle bir durumda, mediyalden laterale doğru posteriorda önemli yumuşak dokulara zarar vermeden çalışılır. Lateralde, her zaman tamamen implant-çimento ayrışımı yapılamayabilir. Bu durumda, ya komponent-çimento ayrışımı ince ve dar osteotomlar ile patellar tendonun lateralinden küçük bir açma (exposure) yapıldıktan sonra lateralden mediyale doğru bir çalışma yapılarak tamamlanabilir ya da, daha çok tercih edildiği gibi, buradaki küçük alandaki çimento tespitini bozmakla uğraşmadan, tibial komponente aksiyel yönde kuvvet uygulayarak komponentin çıkarılması sağlanır. Tibial komponente aksiyel kuvvet uygulamanın çeşitli yolları vardır: implant spesifik veya üniversal kayan çekiçli çıkarıcılar ya da geniş ağızlı aslan dişli kemik klempleri kullanılabilir. Bir diğer yöntem ise, tibial komponenin direkt olarak disimpaktör ile vurularak çıkarılmasıdır (Şekil 6). Yine, geniş ama ince osteotomlar 


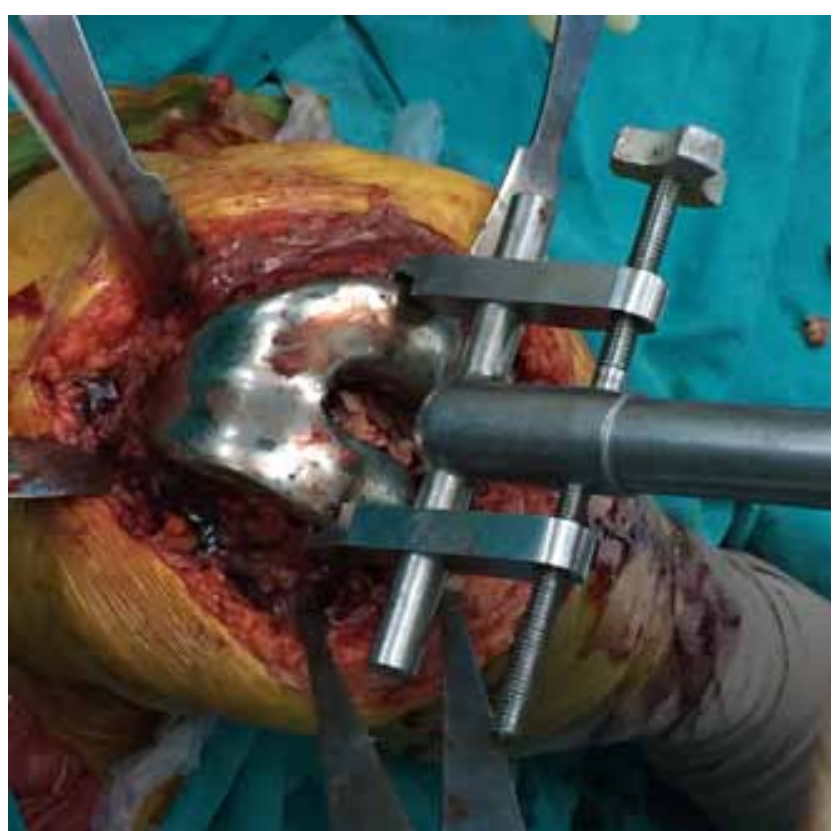

Şekil 5. Femoral komponenti yanlardan tutabilen kayan çekiçli komponent çıkartıcı.

çimento-implant arasında üst üste yerleştirilerek, tibial komponentin çıkarımı sağlanabilir; ancak, bu yöntem uygulanırken, tibial kemiği ezmemeye özen gösterilmelidir. Bir diğer yöntem ise, tibiada, patellar tendonun mediyalinde veya lateralinde küçük bir delik açıp, disimpaktör bu delikten sokularak tibial komponent ayrışımı sağlamaktır. Tüm bu aşamalar, özellikle de tibial komponentin çıkarımı esnasında, metal komponentin femur kondillerine zarar vermesini önlemek için, hiperfleksiyonda tibia öne alınarak çalışılmalıdır.

Çimentosuz tibial implant çıkarımında, kemikimplant arasında testere ile kesi yapılır. Daha sonraki prosedürler çimentolu implant çıkarımı ile benzerdir.

\section{Patellar Komponet Çıkarımı}

Patella küçük bir kemik olduğundan, kemik stok kaybı burada ciddi bir sorun yaratabileceği için, iyi fikse ve uyumlu patellar komponentler çıkarılmayabilir. Birçok patellar komponent, metal arkalık içermeyen, tamamı polietilen, tek veya çok pegli implantlardır. Çimento ile patellar komponent arasından testere ile girilerek, patellar komponent pegleri kesilerek çıkarıldıktan sonra, geriye kalan pegler kolaylıkla kemikten çıkarılabilir. Metal arkalıklı patellar komponent çıkarımı esnasında ise, komponent kemikten ve peglerinden metal kesiciler ile ayrıştıılarak çıkarılır. Geriye kalan metal pegler yerinde bırakılabilir veya çok küçük uçlu burr yardımı ile çıkarılabilir. ${ }^{[6]}$

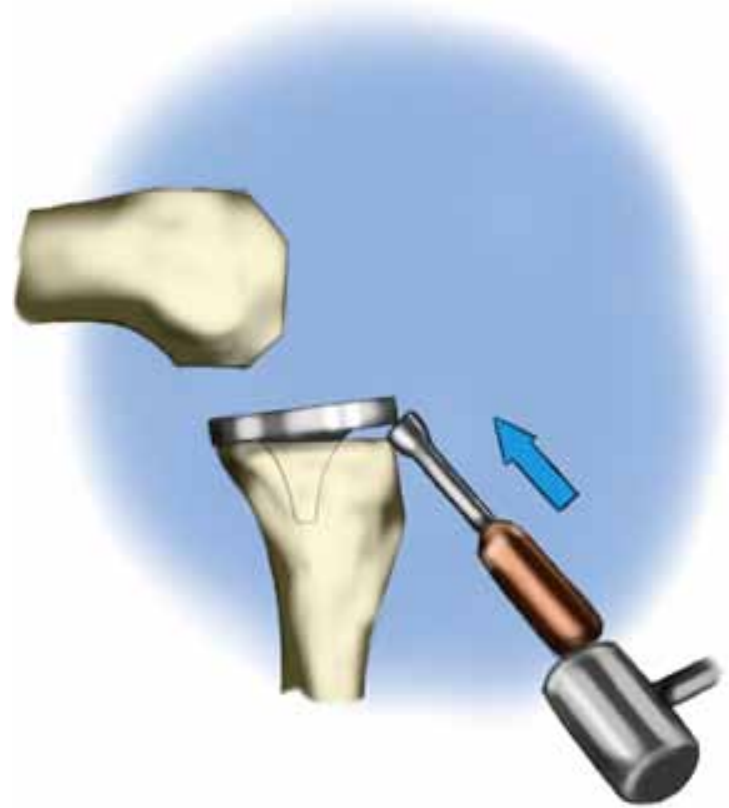

Şekil 6. Tibial komponentin disimpaktör ile çıkarımı.

\section{Intramedüller Stem Çıkarımı}

Özellikle de günümüzde artan oranda karşımıza çıkan rerevizyon cerrahisinde, femoral veya tibial stemler ile karşılaşmaktayız. Bu stemler; uzun-kısa, çimentoluçimentosuz, modüler veya değişik tasarım ya da özellikte olabilir. Femoral kondiller protez veya tibial base plate kemikten ayrıldıktan sonra, aksiyel uygulanan kurvetler sonrasında, bu stemler genellikle bir bütün olarak femoral kondiller implant veya tibial base plate ile beraber çıkabilir. Stemin kendisinin kemiğe iyi tutunduğu gibi bazı durumlarda ise, stem femoral veya tibial komponent ile beraber çıkmayabilir. Bu durumda aksiyel kuwet uygulanması, femoral veya tibial kırık yaratabilir. Femoral veya tibial komponentten öncelikle stemin ayrıştırılması ve steme direkt ulaşım sağlanırsa, stemi çıkarmak kolaylaşabilir. Bu işlem için ya proteze özgü çıkartıcı-ayırıcılar veya metal kesiciler kullanilır. Daha sonra, stem boyunca ultrasonik çimento eriticiler, yüksek hızı burrlar veya uygun el aletleri ile stem-çimento veya stem-kemik arasında çalışılır. Yeterli gevşeme sonrası, stem ucu kemik klempleri veya uygun stemlerin uçlarında bulunan yivlere yerleştirilen vidalara uygun kayan çekiçli disimpaktör yardımı ile, aksiyel kuvvet uygulanarak stem çıkarılabilir. Bazı durumlarda, steme direkt ulaşım sağlanamaz. Total kalça protezi revizyonlarında, femoral komponet çıkarımında olduğu gibi, kemikte osteotomi yapılıp bir pençere açılarak, steme direkt ulaşım sağlanabilir. Yine, tibiada uzatılmış tibial tüberkül osteotomisi yapılabilir. 


\section{Çimentonun Çıkartılması}

Özellikle intramedüller iyi fikse çimento çıkarımı için kullanılacak yöntemler, revizyon kalça cerrahisindeki femoral kanal içerisindeki çimento çıkarımında kullanılanlar ile aynıdır. Çimento kırıcı ve çıkarıcı uzun el aletleri, ultrasonik çimento eriticiler ve yüksek hızlı burrlar bu işlem için kullanılabilir. ${ }^{[3]}$

\section{KAYNAKLAR}

1. Berry DJ. Removal of a well-fixed total knee arthroplasty. In: Lotke PA, Lonner $\mathrm{JH}$, editors. Master Techniques in Orthopaedic Surgery: Knee Arthroplasty. 3. Lippincott Williams and Wilkins; 2009. p.193-202.
2. Maheshwari AV, Tsailas PG, Ranawat AS, Ranawat CS. How to addres the patella in revision total knee arthroplasty. Knee 2009;16(2):92-7. CrossRef

3. Klapper RC, Caillouette JT, Callaghan JJ, Hozack WJ. Ultrasonic technology in revision joint arthroplasty. Clin Orthop Relat Res 1992;(285):147-54.

4. Nett MP, Scuderi GR. Revision of aseptic failed total knee arthroplasty. In: Scott WN, editor. Surgery of the Knee, 5th ed. Philadelphia, PA: Churchill Livingstone; 2011. p.1327-45.

5. Windsor RE, Scuderi GR, Insall JN. Revision of well-fixed cemented, porous total knee arthroplasty. Report of six cases. J Arthroplasty 1988;3 Suppl:S87-94.

6. Dennis DA. Removal of well-fixed cementless metal-backed patellar components. J Arthroplasty 1992;7(2):217-20. 